Studies in African Linguistics

Volume 30, Number 2, Fall 2001

\title{
VOWEL HARMONY IN GUNU
}

\author{
Larry M. Hyman \\ University of California, Berkeley
}

\begin{abstract}
The vowel harmony systems of the Bantu A.60 languages of Cameroon provide an extraordinary wealth of uncommon properties not yet exploited by linguistic theory. In this paper, the author focuses on one variant of the Yambasa cluster, Gunu A.62a, as described by Ambadian [1990, 1991], Orwig [1989], Quilis et al [1990], and Robinson [1979, 1983]. An analysis of long-distance ATR and rounding harmonies in Gunu is presented in terms of the privative features ATR, Front, Round, and Open. Both the featural representations and their "direct mapping" onto outputs account for the derivational opacity as well as transparency of front vowels to Round harmony.
\end{abstract}

\section{Introduction}

The vowel harmony systems of the Bantu A.60 languages of Cameroon provide an extraordinary wealth of uncommon properties not yet exploited by linguistic theory. The best known of these to Africanists is Nen (Tunen), whose unusual ATR system has been studied by a number of researchers [Dugast 1971, Stewart \& Van Leynseele 1979, Mous 1986, van der Hulst et al 1986, Bancel 1991]. In this paper, I present an analysis of vowel harmony in a nearby language, Gunu, based on previous descriptions by Ambadiang [1990, 1991], Orwig [1989], Quilis et al [1990], and Robinson [1979, 1983].1 A member of the of Yambasa group, and designated as A.62a by Guthrie [1967-1971], Gunu bears strong resemblance to Nen, but also exhibits some differences. We shall be concerned with establishing

1 This paper was originally presented at the 3èmes Journées Internationales du GDR "Phonologie" in Nantes on May 30, 2001 and again in a phonology seminar at UC Berkeley. I am grateful for comments received at both presentations. I would especially like to thank Théophile Ambadiang for several very helpful communications and discussions on email, as well as Maarten Mous for sharing his Gunu and other A.40 and A.60 materials with me. Finally, after submitting the original manuscript, I was able to make certain clarifications and revisions influenced by suggestions from an anonymous reviewer and the editor, as well as from papers by Clements [2001] and Dresher [2002ab]. 
a system of underlying vowel representations and an account of the transparent vowel phenomena and derivational opacity which characterize the harmony system in Gunu. To do this, I propose to follow an inductive or "bottom-up" approach where the analysis is guided as directly as possible by the phonological facts of Gunu rather than apriori assumptions about vowel features, vowel harmony, or phonology in general-e.g., whether latter should be derivational or constraint-based. As we shall see, Gunu leads us to some rather interesting conclusions concerning all of these issues.

The paper is organized as follows. In $\S 2$ I present the basic facts concerning the Gunu vowel system, followed by a featural analysis in $\S 3$, and more discussion of the vowel harmony system in $\$ 4$. The implications of these findings are discussed in the summary in $\S 5$, followed by a brief conclusion in $\S 6$.

\section{The basic facts}

To begin, we note that, on the surface, Gunu has the straightforward seven-vowel system in (1). The IPA symbols, adopted in all work on Gunu, are designed to reflect the phonetic values of the seven vowels.

(1) Surface vowel system of Gunu

$\begin{array}{lll}\mathrm{i} & & \mathrm{u} \\ \mathrm{e} & & \mathrm{o} \\ \varepsilon & & \mathrm{o}\end{array}$

Quilis et al [1990:346] measure the average F1 and F2 values of these vowels, which occur both long and short, as in (2) and plot the them within the vowel space. I graph the F1/F2 measurements of their short vowels in (3). From these

(2) Average F1/F2 frequencies of the seven vowels of Gunu

\begin{tabular}{l|rrr|rrr}
\multicolumn{3}{c}{ Short } \\
\cline { 2 - 7 } $\mathrm{i}$ & $\mathrm{F} 1$ & $\mathrm{~F} 2$ & $\mathrm{t}$ & $\mathrm{F} 1$ & $\mathrm{~F} 2$ & $\mathrm{t}$ \\
\cline { 2 - 7 } $\mathrm{e}$ & 265 & 2340 & 9.5 & 261.5 & 2332.0 & 17.3 \\
$\mathrm{e}$ & 330 & 2120 & 9.0 & 350.0 & 2155.0 & 18.5 \\
$\mathrm{a}$ & 500 & 2055 & 9.5 & 535.5 & 2085.0 & 19.5 \\
$\mathrm{o}$ & 720 & 1575 & 10.0 & 789.7 & 1481.5 & 15.8 \\
$\mathrm{o}$ & 490 & 1038 & 9.0 & 513.5 & 1017.1 & 14.7 \\
$\mathrm{u}$ & 386 & 1095 & 10.0 & 400.0 & 1040.0 & 14.0 \\
& 270 & 815 & 8.5 & 330.0 & 795.0 & 17.1
\end{tabular}


(3) Display of Gunu short vowels by F1/F2

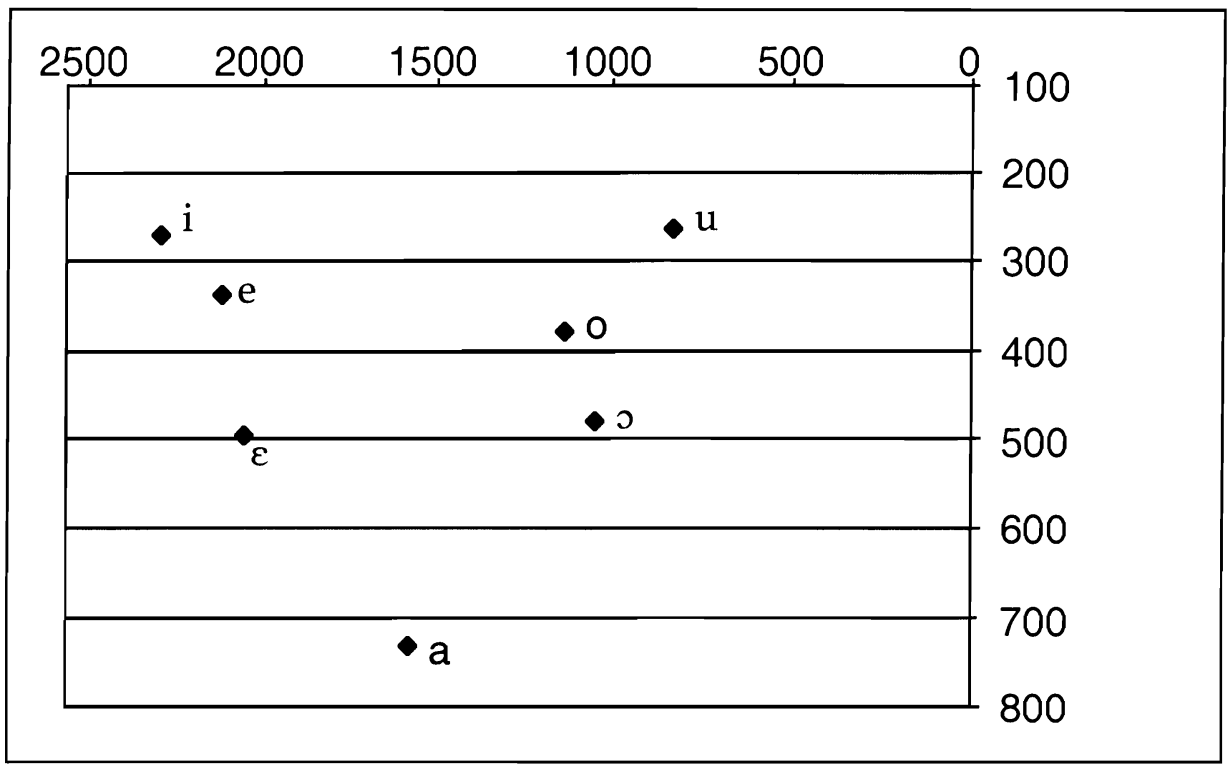

measurements, Quilis et al conclude that the seven vowels group into two sets: $[i, \mathrm{u}, \mathrm{e}, \mathrm{o}]$, which they refer to as "close" vowels, vs. $/ \varepsilon, \mathrm{o}, \mathrm{a} /$, which they refer to as "open" vowels. 2

The goal of this paper is to provide a "bottom-up" analysis of the Gunu vowel system based both on the inventory of vowels as well as the active phonological processes which affect them. While Quilis et al's bipartite division appears to be phonetically justified, the phonological functioning of these vowels tells a quite different story. As shown in (4), based on harmony processes in the language, the seven Gunu vowels divide asymmetrically into three sets: /i, e, u/ vs. / $\varepsilon$, o, a/ vs. /o/. Evidence for this division is shown in (5).

(4) Surface vowel system of Gunu

a.

$\begin{array}{lll} & \text { Set } 1 \\ \mathrm{i} & & \mathrm{u}\end{array}$

Set 2

o

$\varepsilon$
Set 3

0

a

2 I used a linear scale in (3) vs. Quilis et al who use a logorithmic scale. The differences are slight and do not have any bearing on the issues being discussed here. Thanks to Ron Sprouse and Ian Maddieson for help and discussion in plotting the vowels in (3). 
(5) Realization of the final vowel (FV) morpheme /-a/ after all seven of thes underlying vowels

a. $\rightarrow[\mathrm{e}]$ after [+ATR] vowels /i, u, e/

$\begin{array}{llll}\text { bid-e } & \text { 'interrogate' } & \text { bíil-e 'do witchcraft' } \\ \text { fug-e } & \text { 'mix' } & \text { búus-e 'close' } \\ \text { déb-e } & \text { 'flow' } & \text { geem-e 'shine' }\end{array}$

b. $\rightarrow[\mathrm{a}]$ after $/ \varepsilon, \mathrm{o}, \mathrm{a} /$

$\begin{array}{llll}\text { f́m-a } & \text { 'hate' } & \text { lég-a } & \text { 'chat' } \\ \text { fon-a } & \text { 'bless' } & \text { boon-a } & \text { 'uncover' } \\ \text { lab-a } & \text { 'profit from' } & \text { báan-a } & \text { 'feed oneself' }\end{array}$

c. $\rightarrow[0]$ after $/ \mathrm{o} /$

sós-o 'suck' góon-o 'take away a girl in marriage'

In Gunu, as in most Bantu languages, a verb must end with an inflectional final vowel (FV) morpheme, the most common being /-a/. As seen in (5), this FV has three different realizations in Gunu. First, $-a$ is realized as [e] after the vowels $/ i, u$, $\mathrm{e} /$, which justifies their separation from the other vowels. In (2b), $-a$ is realized as [a] after $/ \varepsilon, o, a /$. Finally, in (2c) $-a$ is realized [o] when preceded by $/ \mathrm{s} /$

From these forms we conclude that the FV -a may undergo one of two assimilations to a preceding vowel. The question is what features should be set up to characterize these assimilations. The more straightforward decision concerns $(5 \mathrm{c})$, which shows a very common process of rounding harmony which changes /a/ to [o] when preceded by an $/ \supset /$. (5a) also appears to represent a left-to-right harmony, but it is clear that Quilis et al's phonetic division between [i, e, u, o] and $[\varepsilon, \rho, a]$, based on open/close, does not establish the correct phonological distinctions. The problem is the unusual skewing of the "mid" vowels with respect to the -a to -e change: /e/ conditions the change, while /o/ does not.

While Quilis et al [1990] and Robinson [1983] set up an open/close dichotomy, Ambadiang [1990, 1991] regards the opposition as one of advanced vs. retracted tongue root $([ \pm \mathrm{ATR}])$. In support of Ambadiang's interpretation, dialectally, some speakers realize the [+ATR] variant of /a/ as [ə], suggesting that the primary process is a $\rightarrow$ [ə], while the fronting of [ə] to [e] is a secondary development. Although I have no physiological evidence for how the different Gunu vowels are produced, I shall use the feature ATR as a cover term to refer to the difference in height and/or tense/laxness which characterize the Gunu seven-vowel system. As further developed in $\S 3, / \mathrm{i}, \mathrm{e}, \mathrm{u} /$ will be referred to as ATR and $/ \varepsilon, \mathrm{o}, \mathrm{\rho}, \mathrm{a} /$ as nonATR.

Further effects of the ATR features are shown in (6), where the verb stems on the left should be compared with their corresponding causative forms on the right. Although the alternations require discussion, it would appear that ATR harmony 
also applies right-to-left, triggered by the causative suffix -i-. In $(6 a)$, the root vowels $/ \varepsilon, o, a /$ are realized as $[\mathrm{i}, \mathrm{u}, \mathrm{e}]$, respectively, and the $\mathrm{FV} /-\mathrm{a} /$ is again realized as [e] (dialectally [ə]). In (6b), both rounding and ATR harmony apply to change $/ \mathrm{C} a \mathrm{C}-\mathrm{i}-\mathrm{a} /$ to $[\mathrm{CoC}-\mathrm{i}-\mathrm{o}]$. Since they are already ATR, the root vowels $/ \mathrm{i}, \mathrm{u}, \mathrm{e} / \mathrm{in}(6 \mathrm{c})$ are not further modified by the causative suffix, although again, the final vowel /-a/ is realized as $[\mathrm{e}]$ (or $[ə]$ ).

(6) ATR harmony also operates right-to-left

[e.g., triggered by the causative suffix $-i$-]

a. root vowel is [-ATR] $/ \varepsilon, o, a /$

$\begin{array}{llll}\varepsilon d-a & \text { 'go' } & \text { id-i-e } & \text { 'let escape, save' } \\ \text { bol-a } & \text { 'arrive' } & \text { bul-i-e } & \text { 'send for s.o.' } \\ \text { déán-a } & \text { 'become damaged' } & \text { díen-i-e } & \text { 'damage' } \\ \text { delemena } & \text { 'be standing' } & \text { dilimin-i-e } & \text { 'set upright, align' } \\ \text { fadegena } & \text { 'get up' } & \text { fedigin-i-e } & \text { 'lift up' }\end{array}$

b. root vowel is $[-\mathrm{ATR}] / \mathrm{J} /$

$\begin{array}{llll}d o m b-0 & \text { 'be tired' } & \operatorname{domb-i-o} & \text { 'fatigue' } \\ \text { bol-o } & \text { 'borrow' } & \text { bol-i-o } & \text { 'lend (money)' } \\ \text { hon-o } & \text { 'laugh' } & \text { hon-i-o } & \text { 'make laugh' }\end{array}$

c. root vowel is [+ATR]/i, u, e/

$\begin{array}{llll}\text { sis-e } & \text { 'descend' } & \text { sis-i-e } & \text { 'take down' } \\ \text { húm-e } & \text { 'go out' } & \text { húm-i-e } & \text { 'take out' } \\ \text { ém-e } & \text { 'go out' } & \text { ém-i-e } & \text { 'take out' }\end{array}$

Among the curious facts are the following. First, (6a) shows that the derived ATR analogue to $/ \varepsilon /$ is [i], not [e] as we would expect. Second, (6b) shows that the derived ATR analogue to /o/ is [o], even though underlying /o/ is non-ATR! Third, (6b) also shows that the change of $/ \mathrm{s} /$ to [o] does not bleed rounding harmony, in which case /d $\supset \mathrm{mb}-\mathrm{i}-\mathrm{a} /$ would have been realized $*$ domb-i-e instead of the correct form domb-i-o. This could be effected in one of three ways: (i) apply rounding harmony first, i.e., /domb-i-a/ $\rightarrow$ domb-i-o $\rightarrow$ domb-i-o; (ii) apply ATR harmony first, /domb-i-a/ $\rightarrow$ domb-i-ə, with a subsequent change of [ə] to [o] by rounding harmony; (iii) apply both ATR and rounding harmony simultaneously to the input.

The underlying vowel system and the surface vowel alternations are summarized in (7), where a + indicates that the indicated input and output vowels are ATR. As shown, $/ \varepsilon /, / \mathrm{o} /$, and $/ \mathrm{\rho} /$ each have two alternants, while, due to rounding harmony, /a/ has four alternants (five, if we count [ə]). 
(7) Summary $(+$ in outputs $=[+$ ATR $])$

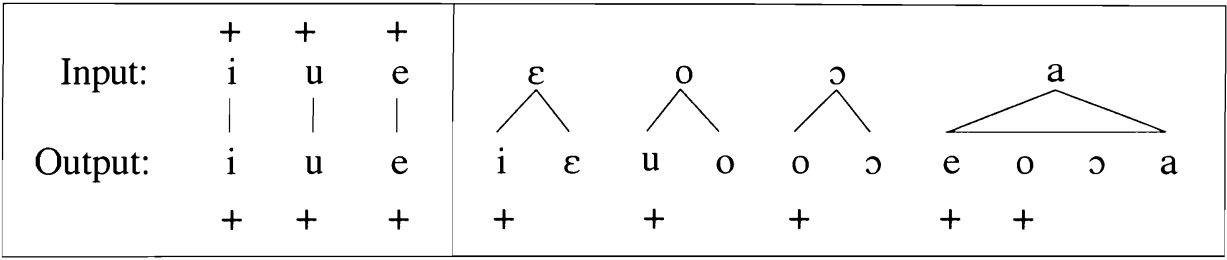

\section{Featural Analysis}

The alternations that were seen in (5) and (6) reveal the following ATR/non-ATR vowel pairs:

$\begin{array}{ll}\mathrm{i} / \varepsilon & \mathrm{u} / \mathrm{o} \\ \mathrm{e} / \mathrm{a} & \mathrm{o} / \mathrm{o}\end{array}$

As shown, [o] is inconsistent with respect to ATR: it is non-ATR in the u/o pairing but ATR in the o/s pairing. Recognizing this, Robinson [1983:55] proposes to divide Gunu surface vowels into the three sets in (9). The question, however, is how to account in a principled way both for [o] and all of the observed alternations.

Robinson [1983]:
a. close
$[i, \mathrm{u}, \mathrm{e}]$
ATR
b. half-close
[o]
ATR / non-ATR
c. open
$[\varepsilon, \rho, a]$
non-ATR

In what follows, I present a proposal based on what we have seen from Gunu as well as from what is known about other Yambasa dialects or languages. ${ }^{3}$ The vowel matrix in (10) summarizes the feature specifications that we have arrived at thus far. (10) only indicates the features that have been shown to be active thus far: /i, u, e/ must be specified with the feature A(TR) and /o/ with the feature R(ound),

(10) Gunu vowel features established thus far (A = ATR; R = Round)

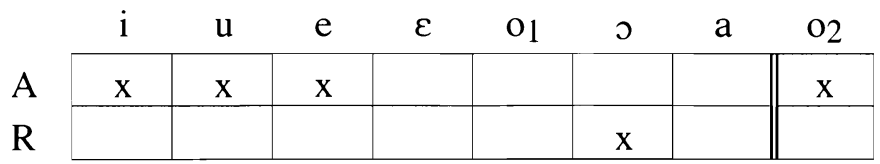

3 See, in particular, Hyman [To appear] for an analysis of Kalong [nu-kàlònè ], originally described by Paulian [1986ab]. 
since those features spread. For clarity, I have distinguished between underlying $\mathrm{lo} /$, designated as $\mathrm{o}_{1}$, which is non-ATR, vs. derived [o], designated as $\mathrm{o}_{2}$, which is ATR. The issue now is to determine what other feature specifications are needed to distinguish front unrounded vs. back rounded vowels, e.g., /i/ vs. /u/, and also vowels which differ contrastively in F1, e.g., /i/ vs. /e/.

As far as I have been able to determine, there is no significant interaction between consonants and vowels that can be of help to us. ${ }^{4} \mathrm{I}$ also have not been able to find additional vowel processes such as coalescence, e.g., /a+i/, /a+u/ $\rightarrow[\mathrm{e}, \mathrm{o}]$, which might be relevant. We therefore are dependent on vowel harmony to guide the analysis. One could imagine establishing the /i///u/contrast as one of Front vs. non-Front or Round vs. non-Round. The variable of [ə] as [e] suggests that Front is active, whereas the rounding harmony conditioned by / $/$ / suggests that Round is active. However, even if we accept that Front and Round are active on these vowels, nothing tells us whether their Front and Round specifications can be extended to the rest of their respective color set. ${ }^{5}$

Since my goal is not contrastive underspecification or minimal specification per se-but rather specification of all active features, I will tentatively adopt the position that the extension of such features is legitimate unless there is evidence to the contrary. ${ }^{6}$ This yields the feature representations in (11).

(11) Gunu vowels specified for ATR, Front and Round

\begin{tabular}{|c|c|c|c|c|c|c|c|}
\hline $\mathrm{i}$ & $\mathrm{u}$ & e & $\varepsilon$ & $\mathrm{O}_{1}$ & 0 & $a$ & $\mathrm{O}_{2}$ \\
\hline $\mathrm{x}$ & $\mathrm{X}$ & $\mathrm{X}$ & & & & & $\mathrm{x}$ \\
\hline$x$ & & (x) & $\mathrm{x}$ & & & & \\
\hline R & $\mathrm{X}$ & & & $x$ & $\mathrm{X}$ & & $\mathrm{X}$ \\
\hline
\end{tabular}

As shown, $I$ have indicated /e/ as $(F)$, since it has the two realizations $[e]$ and [ə]. This leaves three oppositions less than adequately specified: /i/ vs. [e], /u/ vs. $[\mathrm{o}]\left(\mathrm{o}_{2}\right)$, and $/ \mathrm{o} /\left(\mathrm{o}_{1}\right) \mathrm{vs} . / \mathrm{J} /$. All three of these pairs involve vowel height. Recall

4 For example, there is no palatalization that would suggest recognizing a coronal or Front feature. Nearby Nomaante, which has a very similar vowel harmony system to Gunu, does have palatalization of $/ \mathrm{n} /$ to $[\mathrm{n}]$ before both $/ \mathrm{i} /$ and $/ \varepsilon /$. Thus, while Gunu has the class 5 prefix variants ni-/ne-, Nomaante has ni-/ne-[Taylor 1985].

5 Thanks to an anonymous reviewer for pointing out that this would be a deductive rather than inductive move: In terms of their phonological behavior, I have not shown that $/ \mathrm{i} / \mathrm{is}$ Front or that $/ \mathrm{u} /$ is Round. The reviewer also questions whether Gunu unambiguously determines the difference between /a/ and / $/ \mathrm{J}$ as Round rather than, say, Back or Low. It is important to point out, however, that minimal or contrastive specification and activated specification are not necessarily the same thing.

6 As an example of such counter-evidence, Dresher [2002] and Dresher \& Zhang [2002] discuss Western Manchu, which has the vowels /i, u, $,, \supset, a, \partial /$. They present evidence to show that although $/ \mathrm{u} / \mathrm{is}$ ATR, /i/ is not, despite what one expects from its phonetics. Similarly, they argue that $/ \mathrm{J} /$ is phonologically labial, but $/ \mathrm{u} / \mathrm{and} / \mathrm{J} /$ are not. 
that $\mathrm{R}$ will spread only from / $/ \mathrm{a}$ and only onto an /a/. ${ }^{7}$ Assuming, as I have done, that $\mathrm{R}$ is present on all of the rounded vowels, this means that $\mathrm{R}$ harmony has to refer to a feature that is present in $/ \mathrm{J} /$, but not in $/ \mathrm{o} /$. I therefore propose to adopt Clements' [1991] vowel height feature Open, which yields the full Gunu specifications in (12). Since there is no evidence of binarity, I adopt the privative features ATR, Front, Round, and Open, abbreviated AFRO, which are similar to or identical with pro-posals in particle-, dependency-, government-, and (some) autosegmental phonology [Anderson \& Ewen 1987, Goad 1993, Goldsmith 1985, van der Hulst \& Smith 1985, Harris 1990, 1999, Harris \& Lindsay 1995, Kaye, Lowenstamm \& Vergnaud 1985, Rennison 1987, Schane 1984, etc.]. Note also that the above Gunu-motivated features are virtually identical to those proposed by van der Hulst \& van de Weijer [1995] in their overview article on vowel harmony.

(12) Gunu vowels specified for ATR, Front, Round and Open

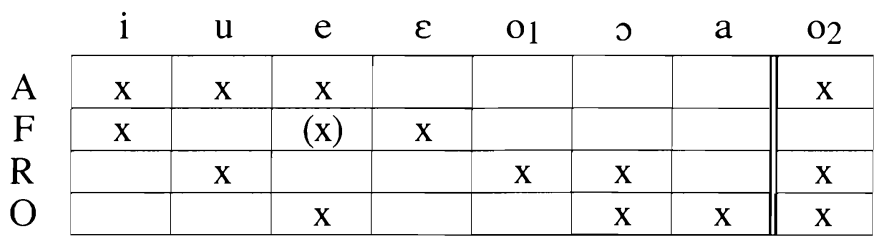

The salient properties of the system in (12) are as follows:

First, there is no need for three contrasting vowel heights in Gunu. Given the role of the ATR feature, two heights will suffice [cf. Rennison 1987]. As indicated, the three vowels /i, u, e/ have the ATR element, while the three vowels /e, o, a/ have the Open element. What this means is that the vowel that alternates between [e] and [ə] is actually /a/ with an ATR feature.

Second, the vowels $/ \varepsilon, \mathrm{o} /$, like $/ \mathrm{i}, \mathrm{u}$ /, lack the Open element. In other words, $/ \varepsilon, \mathrm{o} /$ have the same representation we would have expected if their phonetic values were [I, $\mathrm{U}]$, which do not occur on the surface in Gunu. We might note in this context that there is some variation in the realization of input $/ \mathrm{o} /$, as indicated in (13). Whereas the verbs /domb-a/ 'be tired' and /bol-a/ 'borrow' show rounding harmony (forms in parentheses), the verbs /domb-a/ (variant /domb-a/) and /bol-a/ (variant /bola/) do not. This follows if we assume that $/-\mathrm{a} /$ assimilates in rounding only to $/ \mathrm{J} /$, which has the feature Open, but not to $/ \mathrm{o} /$, which lacks this feature. In some speech variants, in some lexemes, /o/ can be pronounced [o], but without conditioning rounding harmony. 8

7 Or, conceivably, onto its ATR counterpart [e] [ə]. See discussion of (6b) above.

8 Out of the over 500 verbs included in Robinson [1979], 9 appear to involve assimilation of $-a$ to a preceding /o/. On closer examination, however, 7 of these have an internal [n] and one the palatal approximant [j]: bódólonyo 'listen', bónyóonono 'drink with big gulps', bósógolonyo 'pray', nodonyo 'sharpen', óhiginyo 'help', oliminyo 'accept', sóbinonyo 'be ceremonious', and oyoyo 'make live'. Since no verb with a root /o/ ending in a FV -a has either [n] or [j], we can conclude that these palatal consonants carry an ATR feature, which explains why they do not have [o] 
(13) Dialectal realization of /o/ in Gunu
a. Robinson [1983] Orwig [1989] domb-a domb-a 'leave' (cf./domb-a/ $\rightarrow$ domb-っ 'be tired')
b. Robinson/Orwig Ambadiang [1990] bol-a bol-a 'arrive' (cf. /bol-a/ $\rightarrow$ bol-o 'borrow')

Since the Front feature is not required in underlying representations, the input/output relations can be expressed as in (14). As shown, the vowel [o] is the realization of two different featural outputs, $\mathrm{R}$ and ROA. The first of these is underlyingly non-Open, i.e. "/v/" (varying dialectally between [o] and [0]); the second is open and ATR. Turning to the front vowels, although we expect the opposite alignment cross-linguistically, (14) shows that /e/ is Open, while / $/$ / is not. The featural analysis of /e/ is AO, the ATR counterpart to $/ a /$, while $/ \varepsilon /$ is underlyingly featureless. As such, $/ \varepsilon /$ has the featural representation of its historical source, ${ }^{*}$ I.

(14) Particle analysis

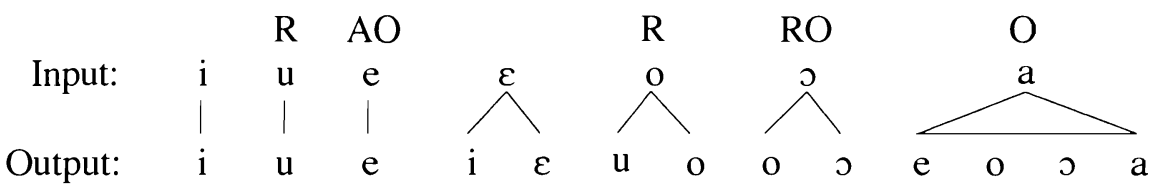

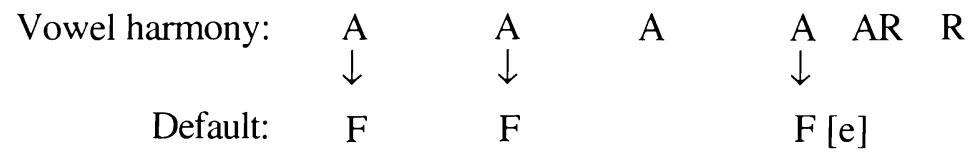

The underlying vowel system can now be summarized as in (15). In other words, the ATR analogue of $/ \mathrm{a} /(=/ \mathrm{e} /)$ is represented as a more close vowel than the non-ATR analogue of $/ \mathrm{i} /(=/ \varepsilon /)$. As implied, however, it would be equally possible to symbolize the "close" vowels as in (16a).

(15) The underlying vowel system

$\begin{array}{rcccc} & \text { a. "Close" Vowels } & \text { b. Open Vowels } \\ \text { ATR: } & \mathrm{i} & \mathrm{u} & \mathrm{e} & \\ \text { non-ATR: } & \varepsilon & \mathrm{o} & \mathrm{a} & \supset\end{array}$

throughout. The one exception is polo 'pierce', which, interestingly, is realized as bolo in Nomaante. 
(16) Alternative symbols for the same underlying system
a. "Close" Vowels
b. Open Vowels

ATR:
non-ATR:

$\begin{array}{ll}\mathrm{i} & \mathrm{u} \\ \mathrm{I} & \mathrm{U}\end{array}$

$\mathrm{e}$

a 0

The symbols /I/ and /U/ can either be thought of as /I, U/ or as underspecified archiphonemes, /U/ being marked only for Round, /I/ being marked Front, or having no underlying features. Either way, the significant fact is that this is not a straightforward /i, e, $\varepsilon, \mathrm{u}, \mathrm{o}, \mathrm{\rho}, \mathrm{a} /$ vowel system. This point is made all the more clear by other facts concerning the vowel harmony processes in Gunu, which we now examine in more detail.

\section{More on Gunu vowel harmony}

As indicated above, Gunu has both ATR- and Round harmony, which have their fullest effect on affixes. We take up suffixes, then prefixes in the following paragraphs.

Other than causative /-i-/, Gunu contrasts three vowels in verb extensions, as indicated in (17). ${ }^{9}$ As in most Bantu languages, the most widespread shape of derivational suffixes (or verb extensions) is -VC-. The vowel of these extensions may be /a/, /I/ or /U/, i.e., any of the three vowels specified for at most one feature: Open, Front, or Round.

(17) Three constrasting vowels in -VC- verb extensions

a. lal : -an- 'plural, iterative'

b. I/ -In- 'applicative'

-Ig- 'intensive, intransitive'

-Id- 'diminutive'

-Im- 'stative'

c. $/ \mathrm{U} / \mathrm{:} \quad-U g$ - 'reversive intr.'

-Un- 'reversive tr.'

-Um- '?'

As in the case of the FV -a, the /a/ of the -an- extension may undergo ATR and/or Round harmony, shown in (18). (18a) and (18c) also show that Round harmony is iterative. Compare also the realizations of 'plural, iterative' -an-and the FV $-a$ in the related verbs in (19).

(18) /a/ of -an- may undergo ATR and/or Round harmony
a. R only : /gos-an-a/ $\rightarrow$ gos-os- $\supset$ 'descend continuously'
b. A only : /gumb-an-a/ $\rightarrow$ gumb-en-e 'seize'
c. R, A : /nod-an-i-al $\rightarrow$ nod-on-i-o 'sharpen'
d. Neither : /mám-an-a/ $\rightarrow$ mám-an-a 'be silent'

9 The examples presented in this section are taken from Orwig [1989]. For further exemplification of the different extensions in Gunu, see Ambadiang [1990:510-518]. 
(19) Round harmony is "iterative", seen with the extension -an-
a. $\zeta b-\supset$ 'sense'
b. '́b-on-っ 'understand' gos-っ 'descend'
gos-on-っ 'descend continuously'

The iterative effect of Round harmony can also be seen on verb forms with lexicalized -an-which do not have a corresponding shorter base, as in (20).

(20) Frozen forms with the extension /-an-/ also show iterative Round harmony

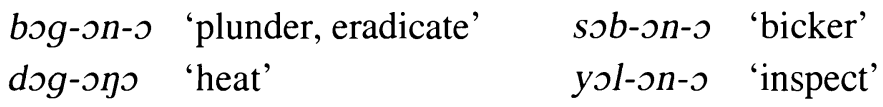

Turning to the next suffix vowel, the /I/ of -IC- extensions is realized [i] in the presence of ATR, otherwise [ $\varepsilon]$, as shown in (21).

(21) /I/ is realized [i] in the presence of ATR, otherwise [ $\varepsilon$ ]
a. /kún-Id-a/ $\rightarrow$ kún-id-e
'fold, twist'
/lib-Ig-a/ $\rightarrow$ lib-ig-e 'drench, wet, drink' (cf. lib-e 'to water')
/kéc-Im-a/ $\rightarrow$ kéc-im-e 'range, classify'
lgud-Im-In-a/ $\rightarrow$ gud-im-in-e 'bend over'
b. /nog-In-a/ $\rightarrow$ nog-en-a 'plait for (s.o.)' (cf. nog-a 'plait')
/fól-Id-a/ $\rightarrow$ fól-ed-a 'sweep a little' (cf. fól-a 'sweep')

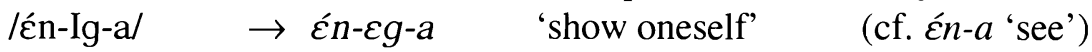
/sag-Im-a/ $\rightarrow$ sag- $\varepsilon m-a \quad$ 'shiver'
c. /fad-Ig-In-a/ $\rightarrow$ fad- $\varepsilon g-\varepsilon n-a$ 'get up, leave'
$/$ fad-Ig-In-i-a/ $\rightarrow$ fed-ig-in-i-e 'lift up, raise'

In addition, the unspecified (or F-specified) vowel /I/ is transparent to Round harmony. In (22a), the FV -a becomes [0] through the [ $\varepsilon]$ of the -In-suffix. In (22b), both the extension -an- and the FV -a undergo Round harmony through a -IC- extension, while in (22c), the FV -a undergoes Round harmony through two -IC- extensions. We see the same in (22d), where the resulting FV also undergoes ATR harmony to $-o$.

(22) The unspecified vowel /I/ is transparent to Round harmony
a. /bol-In-a/ $\rightarrow$ bol-en-o

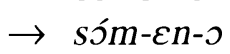
'borrow for (s.o.)'
/sóm-In-a/
'advise'
(cf. bol-o 'borrow')
/gos-In-a/
$\rightarrow$ gos-En-०
'descend a slope'
(cf. sóm-っ 'accuse')
(cf. gos-っ 'descend') 


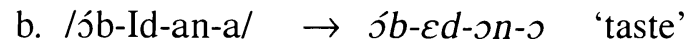
(cf. $\zeta b-\supset$ 'sense, hear')
/ób-Ig-an-a/ $\rightarrow$ ób-eg-on-っ 'suffer'
/ób-In-an-a/ $\rightarrow$ ób-en-on-o 'possess'

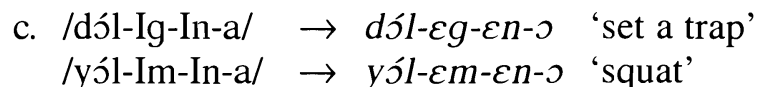

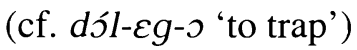
d. /ol-Im-an-i-a/ $\rightarrow$ ol-im-on-i-o 'believe, accept'
/bol-an-In-i-a/ $\rightarrow$ bol-on-in-i-o 'lend'
/ób-In-i-a/ $\rightarrow$ ób-in-i-o 'make obey'
(cf. $\zeta b-\supset n-\varepsilon n-\supset$ 'obey')

The nouns in (23) show that Round harmony also applies right-to-left, again going through /i/ and /I/ [Ambadiang 1990]. In (23a) we see the unaffected class 6a prefix /ma-l. In (23b) the FV morpheme - 0 causes this prefix to become mo-. The underlying forms in (23c) are /ma-fit-s/ and /ma-bit-o/. As shown, the rounding of the class 6 a prefix mo- is conditioned by the FV - 0 , while the ATR is conditioned by the roots. 10

(23) Round harmony also applies right-to-left through /i/ and /I/ [Ambadiang 1990]
a. /ma-báayI/ $\rightarrow$ ma-báaye 'milk' /ma-kánya/ $\rightarrow$ ma-kánya 'suffering, illness'
b. /ma-lIn-১/ $\rightarrow$ mo-leno 'adornment'
c. /ma-fit-s/ $\rightarrow$ mo-fito 'lead' /ma-bín-ə/ $\rightarrow$ mo-bíno 'dance' (cf. le -a 'adorn') (cf. bín-e 'to dance')

Recall, as shown in (24), that /o/ does not condition Round harmony, whether locally or at a distance. What this means is that the /o/ of the roots in (24) must not have the same representation as the output [o] of (23c). In (12) it was proposed that underlying /o/ $\left(\mathrm{o}_{1}\right)$ is specified only for Round, while the vowel [o] $\left(\mathrm{o}_{2}\right)$ that derives from /o/ via ATR harmony, or from /a/ via ATR and Round harmony, is specified as ROA.

(24) /o/ does not condition Round harmony (local or at-a-distance)
a. /fól-Id-a/ $\rightarrow$ fól- $\varepsilon d-a$ 'sweep a little'
(cf. fól-a 'sweep')
b. /nog-In-a/ $\rightarrow$ nog-en-a 'plait for (s.o.)'
(cf. nog-a 'weave (basket)')
c. /gón-In-a/ $\rightarrow$ gón- $\varepsilon n-a$ 'mature'
(cf. gón-a 'plant')

As seen, Round harmony is "parasitic" on Open: it obtains only between input Open vowels. As has been seen previously, an affixal [a] is ill-formed on either side of a stem $/ \mathrm{s} /$, possibly separated from the latter by [i] or [ $\varepsilon$ ]. The proposal in

10 Théophile Ambadiang reports in personal communication that $\mathrm{R}$ harmony is variable on

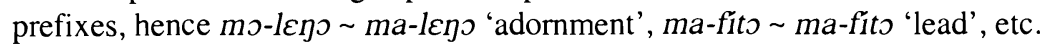


(25a) is that Open vowels define a "plane" which defines where $\mathrm{R}$ harmony can occur. The non-Open vowels $/ \mathrm{i} /$ and $/ \mathrm{I} /$, i.e., $[\mathrm{i}, \varepsilon]$, are transparent to Round harmony, as shown in (25b). In addition, $\mathrm{C} \varepsilon \mathrm{C} \supset$ and $\mathrm{C}\lrcorner \mathrm{C} \varepsilon$ stems occur in nouns, e.g.,

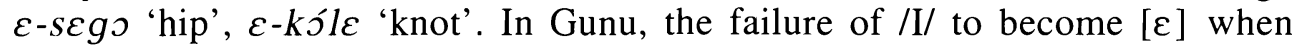
adjacent to $/ \mathrm{s} / \mathrm{can}$ be due to the fact that it is underlyingly non-Open. One does not have to say that preservation of an input Front feature is involved, which, if $\mathrm{R}$ is assumed to be active on all round vowels, is clearly not needed in the underlying representations. ${ }^{11}$

(25) Round harmony as bidirectional spreading of $\mathrm{R}$
a. local (iterative) harmony
b. harmony "at a distance"
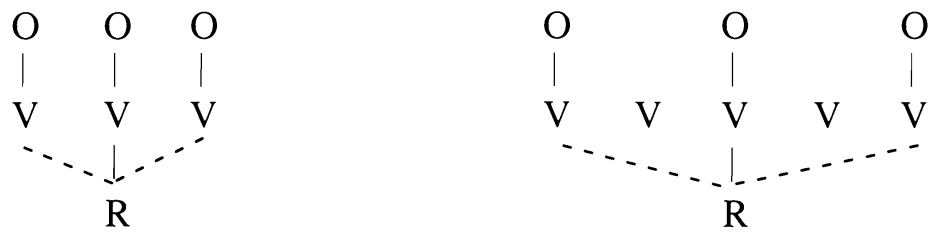

Given that Round harmony can penetrate through $[\mathrm{i}]$ or $[\varepsilon](/ \mathrm{I} /)$, it is surprising that the /U/ of -UC- extensions seen in (17c) blocks Round harmony. The examples in (26) show how these extensions are realized after different root

(26) /U/ of -UC- extensions blocks Round harmony

a. /-UC-/ $\rightarrow$ [-uC-] after ATR vowels /i/, /u/ and /e/

/giy-Um-In-i-a/ $\rightarrow$ giy-um-in-i-e 'know'

/gund-Um-a/ $\rightarrow$ gund-um-e 'thunder'

/fúg-Un-a/ $\rightarrow$ fúg-un-e 'erase'

lgúl-Ug-a/ $\rightarrow$ gúl-ug-e 'return home'

lén-Ug-a/ $\rightarrow$ én-ug-e 'be healed'

b. /-UC-/ $\rightarrow$ [-oC-] after non-ATR vowels /U/ [o] and /a/

$\begin{array}{llll}\text { /fUf-Un-a/ } & \rightarrow \text { fof-on-a } & \text { 'burn hair' } \\ \text { /kÚc-Un-a/ } & \rightarrow \text { kóc-on-a 'cough' } \\ \text { /mám-Un-a/ } & \rightarrow \text { mám-on-a } & \text { 'make another in palmtree' } \\ \text { /san-Un-a/ } & \rightarrow & \text { san-on-a } & \text { 'deny' }\end{array}$

11 This solution cannot be applied to closely related Kalong, which clearly has active F and R, as well as $/ \mathrm{I} /$ contrasting with Open $/ \varepsilon /$, and the latter still does not undergo R harmony [Hyman, To appear]. 
(26) c. /-UC-/ $\rightarrow[-\supset C-]$ after non-ATR Open vowel /o/

$\begin{array}{lll}\text { /yən-Um-a/ } & \rightarrow \text { yon-om-a } & \text { 'have a good time, play' } \\ \text { /foy-Ug-a/ } & \rightarrow \text { foy-og-a } & \text { 'wake (self) up' } \\ \text { /foy-Un-a/ } & \rightarrow \text { foy-on-a } & \text { 'wake up (s.o.)' } \\ \text { /yog-Um-a/ } & \rightarrow \text { yog-om-a } & \text { 'make a jumbled noise' }\end{array}$

vowels. As shown in (26a), /-UC-/ is realized [-uC-] after the ATR vowels /i/, /u/ and /e/, as expected. Also as expected, in (26b), /-UC-/ is realized [-oC-] after the non-ATR vowels /U/, [o] and /a/.12 In (26c), however, we see that /-UC-/ is realized [-っC-] after the root vowel $/\lrcorner /$, a case of Open harmony which is parasitic on Round. As noted, an [0] derived by Open harmony does not pass on its Round feature to the FV -a. Minimal pairs occur such as the one in (27). The -an-a sequence becomes - on- $\supset$ after / $/$ by Round harmony in $(27 \mathrm{a})$, but the $-U n-a$ sequence becomes -on-a by Open harmony in (27b).

(27) Minimal pair

a. /dón-an-a/ $\rightarrow$ dón-on-s 'call, invite, pronounce'

b. /don-Un-a/ $\rightarrow$ don-on-a 'do a traditional ceremony to chase away evil'

The proposed solution is as follows: Round harmony is parasitic on INPUT Open targets and triggers only-not on the feature Open derived by height harmony in (26c). This is shown in (28). Round harmony does not apply in (28a) because the /I/ target vowels are not Open. It does not extend from the /U/ in (29b), because this latter vowel is not Open in the input. ${ }^{13}$

(28) a. no harmony because of target /I/

b. no harmony because of trigger/U/

\begin{tabular}{|c|c|c|c|c|c|c|c|c|}
\hline \multirow{5}{*}{ V } & \multicolumn{2}{|l|}{$\mathrm{O}$} & \multicolumn{2}{|c|}{$\mathrm{O}$} & \multicolumn{2}{|c|}{$\mathrm{O}$} & \multicolumn{2}{|l|}{$\mathrm{O}$} \\
\hline & | & & | & & | & & 1 & \\
\hline & V & V & V & V & V & V & V & \\
\hline & | & & & & | & & & \\
\hline & $\mathrm{R}$ & & & & $\mathrm{R}$ & & & \\
\hline$\Lambda$ & 0 & V & 10 & & $\mathrm{U}$ & & a/ & (input) \\
\hline$\downarrow$ & & $\downarrow$ & & & $\downarrow$ & & & \\
\hline$\varepsilon$ & & $\varepsilon$ & & & 0 & & & (output) \\
\hline
\end{tabular}

12 I have not found any examples of -UC- after $/ \mathrm{I} /$ in the data at my disposal.

13 An anonymous reviewer has suggested that $R$ harmony fails to extend in (28b) because the $R$ feature that would spread is not from the stem-initial vowel, but rather the second vowel of the stem. A stem-initial R, on the other hand, will spread onto a continuous sequence of syllables with $/ \mathrm{a} /$. We know from other Bantu languages that mine is the historically correct analysis, but we cannot dismiss this other possibility, which has analogues outside Bantu. 
Finally, let us return to the different behavior of -IC- vs. -UC-extensions with respect to Round harmony. In (29a) we have what appears to be a case of what Archangeli \& Pulleyblank [1994] term "antagonistic transparency". The F feature is incompatible with $\mathrm{R}$, since Gunu does not allow front rounded vowels. Still, $\mathrm{R}$ harmony goes through an /i/ or /I/. In (29b), on the other hand, repeated from (28b), even though the second vowel becomes $\mathrm{O}$ by height assimilation, its $\mathrm{R}$ feature does not continue on the following vowel $/ \mathrm{a} /$. What this means is that $/ \mathrm{O} /$ may not assimilate an /a/ through an /U/. Since /U/ is itself Round, Archangeli \& Pulleyblank [1994] would refer to such an occurrence as "sympathetic transparency." Is this a good result? In other words, do the two kinds of (potential) transparency have a bearing on our analysis?

(29) a. antagonistic transparency

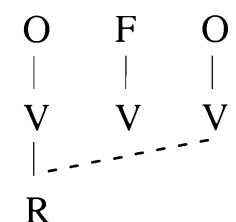

$\begin{array}{lll}10 & \text { I } & \text { a/ } \\ & \downarrow \\ & 0\end{array}$ b. no sympathetic transparency
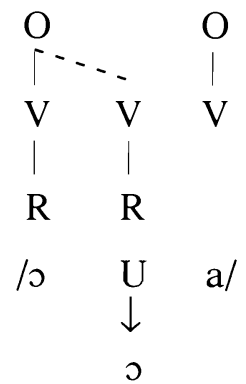

(input)

(output)

In response, the problem is that the feature $\mathrm{F}$ was not really justified on $/ \mathrm{i} /$ and /I/. If $\mathrm{R}$ is assumed on $/ \mathrm{u}, \mathrm{U}, \mathrm{o} /$, then $\mathrm{F}$ is not needed (except to derive [e], the predominant variant of [ə], as the ATR counterpart to /a/). If we remove the $\mathrm{F}$ from (29a), there is no antagonism at all. In fact, /I/ would have no vowel features, while /i/ would be specified only for ATR. Given that Gunu has Round harmony but not Front harmony, evidence seems to be converging on $\mathrm{R}$ being more activated than $\mathrm{F}$ - which may not be present in the phonological system at all.

\section{Summary and discussion}

There are three components to the analysis offered in the preceding sections: (i) the proposed vowel representations; (ii) the proposed vowel harmony processes (input/ output relations); (iii) the treatment of transparent vs. opaque vowels, e.g., why /sóm-In-a/ is realized sóm- $\varepsilon n-\supset$ 'advise' (transparency of /I/), but /foy-Un-a/ 'wake up (s.o.)' is realized foy-on-a, not *foy-on-っ (opacity of /U/).

First, concerning the vowel representations, (30) presents the resulting vowel representations if $F$ is not present phonologically. In these representations, @ stands for the Aperture node, which groups Open and ATR [cf. Hyman 1988, Odden 1991, Goad 1993, Clements \& Hume 1995, inter alia] and (C) stands for the Color node, which dominates Round (and ultimately Front). As shown, phonetic [o] derives from two different sources. Once this is accepted, the system consists of the four pairs of ATR/non-ATR output vowels as shown above in (16). 
(30) Representation of the Gunu vowels

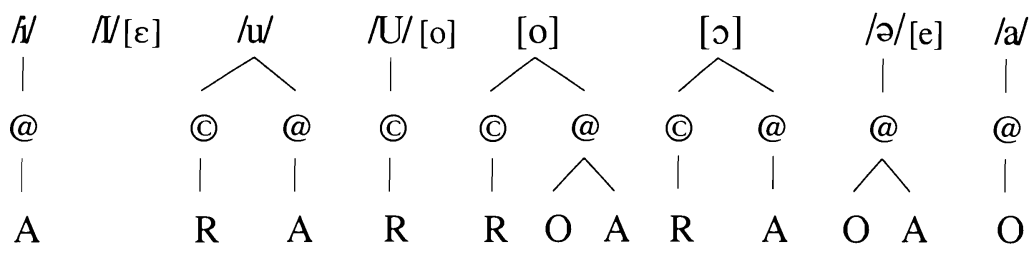

The following arguments support the vowel representations for /I/ and /U/:

First, only phonologically active "elements" are recognized in above vowel representations: A for ATR harmony, $\mathrm{R}$ for Round harmony, and $\mathrm{O}$ for the parasitic relation to Round harmony.

Second, these representations account for the non-ATR behavior of /U/ [o], which is distinct from both $/ \mathrm{u} /$ and $/ \mathrm{o} /$.

Third, the less complex featural complexity of /i/ and /I/ correlates with their unique transparency to Round harmony. More complex vowels are not transparent in this way. Specifically /U/, which is specified for Round, is not transparent.14

Fourth, the lack of an Open (and Front) feature on $[\varepsilon]$ accounts for why there is no parasitic Front harmony as in other Yambasa dialects, e.g., Kalong [Paulian 1986ab; Hyman, To appear]. As shown in (31a), like Gunu, Kalong has Round harmony. As shown in (31b), however, Kalong also has Front harmony. Therefore, Kalong must have both active features Front and Round. Also note that Kalong has the nine underlying vowels /i, I, e, $\varepsilon, \mathrm{u}, \mathrm{U}, \mathrm{o}, \mathrm{o}, \mathrm{a} /$, an inventory which forces $/ \varepsilon /$ to have an Open feature on which Front harmony is parasitic.

(31) Round and Front harmonies in Kalong
a. kù-pós-à $\rightarrow$ kù-pós-ò 'bark' kù-kòk-à $\rightarrow$ kù-kj̀k-j̀ 'pull'
b, kù-fén-à $\rightarrow$ kù-fén-è 'disdain' kù-sél-à $\rightarrow$ kù-sćl-è 'peel'

The argument against positing the fully specified vowels $/ \mathrm{I} /$ and $/ \mathrm{v} /$ is one of abstractness: How would speakers "know" that they have underlying [-ATR] high vowels, which they never hear? By contrast, by setting up /I/ and /U/, the only claim being made is that speakers know that /I/ is Front and /U/ is Round. The ATR and Open features are determined by context.

Of course, these vowels have the properties they do because Gunu does not allow $/ \mathrm{I} /$ and $/ \mathrm{v} /$. Given the privative features assumed in this study, how can we relate the $[\varepsilon, o]$ realizations of $/ \mathrm{I}, \mathrm{U} /$ to the widely accepted constraint $*[+$ high,

14 This account will, however, not work for Kalong, where /V/ is specified for Front and /U/ for Round, but where both vowels are transparent to both Front and Round harmony [Hyman, To appear]. 
-ATR] [Archangeli \& Pulleyblank 1994, Calabrese 1993]. One possibility, also considered by Archangeli \& Pulleyblank, is to assume that the $[\varepsilon$, o] non-ATR realizations of $/ \mathrm{I}, \mathrm{U} /$ are produced by phonetic implementation. The realization of /U/ as [o] after /o/ might also be viewed this way-thereby accounting for the derivational opacity pointed out with respect to the forms in $(27 \mathrm{c})$.

Another alternative, however, builds on the view in (30) that ATR and vowel height (here, Open) both occur under an Aperture node. With this assumption, one can introduce the Aperture Constraint in (32).

(32) Aperture Constraint (Gunu, Kalong)

An output vowel must have Aperture (i.e., an A or O feature)

While this works without further complication for Kalong, in Gunu one would have to assume that the [o] realization of / $\mathrm{U} /$ in (30) is ROA, not just R. Languages in which the Aperture Constraint is not in effect either have surface $/ \mathrm{I} /$ and $/ \mathrm{v} / \mathrm{or}$ have a different featural analysis (e.g., with RTR as the active feature-cf. Casali [2001] and references cited therein).

Finally, as a further indication of the generality of this analysis, which has been mostly based on alternations within the verb, consider in (33) the surface vowel distributions in 665 bisyllabic nouns in Gunu. As shown, except for / $/$, all vowels in the first stem syllable can be followed by exactly three different vowels in the second syllable. 15 With this one exception, each combination of the seven underlying vowels in the stem-initial syllable allows one Front, one Round, and one Open vowel in the following syllable, as summarized in (35).

\begin{tabular}{|c|c|c|c|c|c|c|c|}
\hline \multicolumn{8}{|c|}{$\mathrm{V} 2$} \\
\hline & $\mathrm{i}$ & $\mathrm{e}$ & $\varepsilon$ & $\mathrm{u}$ & o & 0 & $\mathrm{a}$ \\
\hline $\mathrm{i}$ & 25 & 13 & & & 27 & & \\
\hline $\mathrm{e}$ & 22 & 11 & & 14 & & & \\
\hline$\varepsilon$ & & & 43 & & & 10 & 31 \\
\hline $\mathrm{u}$ & 15 & 35 & & 24 & & & \\
\hline o & 21 & & & & 13 & & 39 \\
\hline 0 & & & 18 & & & 111 & (3) \\
\hline $\mathrm{a}$ & & & 25 & & & 41 & 124 \\
\hline
\end{tabular}

15 The three noun stems of the shape CoCa are considered to be exceptional, possibly due to language or dialect borrowing: ge-bongá 'earring' (cf. imbungá in closely related Tuki), mmonga 'manioc' (cf. $\varepsilon m b o \eta \jmath$ in Nomaante). I haven't found a cognate of ge-sómba 'adult (40 years old)' in any neighboring language. 


\begin{tabular}{|c|c|c|c|}
\hline \multicolumn{4}{|c|}{$\mathrm{V} 2$} \\
\hline \multirow[b]{2}{*}{$\mathrm{V} 1 \mathrm{i}$} & $\mathrm{F}$ & $\mathrm{R}$ & $\mathrm{O}$ \\
\hline & $\mathrm{CiCi}$ & $\mathrm{CiCo}$ & $\mathrm{CiCe}$ \\
\hline $\mathrm{e}$ & $\mathrm{CeCi}$ & $\mathrm{CeCu}$ & $\mathrm{CeCe}$ \\
\hline$\varepsilon$ & $\mathrm{C} \varepsilon \mathrm{C} \varepsilon$ & $\mathrm{CeC}$ & $\mathrm{C} \varepsilon \mathrm{Ca}$ \\
\hline $\mathrm{u}$ & $\mathrm{CuCi}$ & $\mathrm{CuCu}$ & $\mathrm{CuCe}$ \\
\hline o & $\mathrm{CoCi}$ & $\mathrm{CoCo}$ & $\mathrm{CoCa}$ \\
\hline 0 & $\mathrm{C \jmath C} \varepsilon$ & & \\
\hline $\mathrm{a}$ & $\mathrm{CaC} \varepsilon$ & $\mathrm{CaC}$ & $\mathrm{CaCa}$ \\
\hline
\end{tabular}

As shown, after V1 [ $\varepsilon, 0, a]$, a V2 that is F or R will be Open, i.e., [ $\varepsilon$ ] or [0], the latter merging with input $/ \mathrm{CoCa} /$ because of Round harmony. It would be tempting to set up the $\mathrm{V} 2$ as limited to /I/, /U/, or /a/. However, nominalizations show that this would be difficult, e.g., concerning V2 Round vowels in (35).

(35) Deverbal nouns taking a Round suffix 16

$\underline{\text { noun }}$

a.

b. gi-lun-ú 'old'

$u$-fuf-u 'wind'

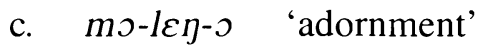

on-end-o 'voyage'

ge-fám-ó 'ransom'

m-mag-s 'chance, luck'

n-námb-ó 'sauce, cooking'

d. do-hon-っ 'laughter'

E-sóm-s 'advice'

$o-n o ́ b-\jmath \quad$ 'fishing' $\underline{\text { verb }}$

bín-e 'dance'

lun-e 'be old'

fuf-en-e 'blow' (wind)

len-a 'adorn'

End-a 'travel, walk'

fán-a 'deliver a ransom'

mag-a 'try'

námb-a 'cook'

hon-o 'laugh'

sóm-o 'advise'

nób-つ 'fish'

Deriving historically from Proto-Bantu *- 0 , the R feature of this suffix - which we saw in $(23 \mathrm{~b}, \mathrm{c})$ - can produce harmony in a ma- prefix, e.g., /ma-lIn-د/ $\rightarrow \mathrm{mo-}$

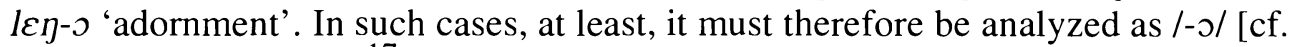
Ambadiang 1990:492]. ${ }^{17}$

16 The vowels in noun prefixes show the following ATR/non-ATR pairings: i-/E-, u-/o-, e-/a-.

17 Such nominalizations do not appear to be very productive, and there are some difficulties in interpretation (also involving tone). The two ATR examples Ambadiang gives retain the -e of the 
Similarly, it is clear that an ATR suffix $-i$ is required to derive agentive (and certain other) nouns from verbs [Ambadiang 1990, 1991], as shown in (36). There are only a few deverbal nouns that take $-I$ in an unambiguous way, e.g., ón-o 'write' $\rightarrow \eta g$ - $\zeta \eta-\varepsilon$ 'writing'. The best that can be said, therefore, is that no CVCV stem contrasts more than three vowels in V2 position.

(36) Deverbal nouns taking an -i suffix

noun

a.

$u \eta g-i ́ b-i \quad$ 'thief'

u-big-i 'carrier'

$u$-be $\eta-i \quad$ 'one who takes care of'

$u$-ben-i 'reader'

$u$-bul-i 'one who arrives'

$u$-nób-i 'fisherman'

b. bu-íb-i 'theft'

cig-í 'insult'

$u$-sun-i 'wind per anum'

$d u-n u d-i$ 'vomit' verb

íb-e 'steal'

beg-a 'carry'

ben-e 'take care of'

ban-a 'read'

bol-a 'arrive'

$n o ́ b-0$ 'fish'

íb-e 'steal'

$s \varepsilon g-a \quad$ 'insult'

sun-e 'pass gas'

nod-a 'vomit'

\section{Conclusion}

As indicated in the introduction, the goal in this paper has been to present an inductive analysis of the vowel system of Gunu. Rather than starting with an assumption of which vowel features should be used, and whether they should be binary, privative or other, the attempt has been to let the facts of Gunu guide the analysis. The result achieved is "bottom up" in the sense that Gunu itself points us towards specific underlying representations, e.g., /I, U/, as well as to the privative elements $\mathrm{A}, \mathrm{R}, \mathrm{O}$ (and possibly $\mathrm{F}$ ) in underlying representations. As we have seen, the features $/ \mathrm{A} /$ and $/ \mathrm{R} /$ spread, not their opposite values. In addition, any input $/ \mathrm{A} /$, $/ \mathrm{R} /$, or $/ \mathrm{O} /$ will be "faithful" in the output: there is no deletion or delinking of these elements, which always surface as such. Assuming these elements, there is a "monotonic" relation between input and output, since the latter will include anything that was there in the input. Finally, we have seen that the feature [O] can be inserted, e.g., to convert /I/ to [ $\varepsilon$ ], but only in response to the Aperture Constraint in (32).

verb: kúl-e 'visit' $\rightarrow$ u-kúl-e 'a visit', súg-e 'reach its end' $\rightarrow$ u-súg-e 'end'. An /-U/ analysis would have predicted ${ }^{*} \mathrm{u}$-kúl-u, ${ }^{*} \mathrm{u}$-súg-u. In any case, the Proto-Bantu/Gunu correspondence $* \mathrm{v}$ $>[0]$ is clearly correct, e.g., *tátu > gá-dàdó 'three', *-dúme 'male' > o-nóme 'husband', *-yúdu > nyoóno 'nose' (cf. *-túku > bu-dúgú 'night'). 
The account we arrive at in this way also has one other interesting property: The correct input-output relations can be stated without derivationality. The observed counterfeeding Input/Output relations result from the "direct mapping" [Kenstowicz \& Kisseberth 1979] of input onto output, i.e., the realizations of /U/ as [0] by height harmony in (26c) does not feed Round harmony, and its default realization as [o] does not condition ATR harmony. There must, of course, be iterativity to get multiple applications of ATR and Round harmony, but there is no feeding or bleeding attested in the phonology of Gunu. Such situations are easily handled by two- and three-level systems such as those of Goldsmith [1993a], Karttunen [1993], and Lakoff [1993]. Since the kind of opacity reported here appears to be widespread in the Bantu A.40 and A.60 languages of Cameroon, this suggests another kind of "conspiracy" in phonology: the conspiratorial non-interaction, i.e., non-feeding and non-bleeding, of phonological input-output relations. In short, some languages like opacity (counterfeeding, counterbleeding), which is massively attested also with respect to tone in Haya [Hyman 1993]. Given such systems and the issues that arise in their treatment within optimality theory (see McCarthy [1998] and references cited therein), the question naturally arises of just how much can or should be accounted for in strictly output-driven terms.

\section{REFERENCES}

Ambadiang, Théophile. 1990. “A non-linear account of vowel harmony in Gunu (Bantu A.62)." Ms.

Ambadian, Théophile. 1991. "La oposicion flexion-derivacion en la morfologia del nombre bantu con especial referencia al gunu (Bantu A62)." Ph.D. dissertation, Universidad Complutense de Madrid.

Archangeli, Diana and Douglas Pulleyblank. 1994. Grounded Phonology. Cambridge: MIT Press.

Bancel, Pierre. 1991. "Floating morphemes in Nànì." In Kathleen Hubbard (ed.), Berkeley Linguistic Society 17S: Proceedings of the Special Session on African Language Structures. Berkeley: BLS. Pp. 3-14. 
Boone, Douglas W., David P. Bradley, and Caroline A. Grant. 1992. Central Yambasa survey report. Summer Institute of Linguistics. (http://gamma.sil.org/ silesr/1999/009/Yambassa.html)

Calabrese, Andrea. 1993. "A constraint-based theory of phonological markedness and simplification procedures." Linguistic Inquiry 26.373-463.

Casali, Roderic F. 2001. "ATR dominance and vowel inventory structure." Ms. SIL.

Clements, G.N. 1991. "Vowel height assimilation in Bantu languages." In Kathleen Hubbard (ed.), Berkeley Linguistic Society 17S: Proceedings of the Special Session on African Language Structures. Berkeley: BLS. Pp. 25-64.

Clements, G. N. 2001. "Representational economy in constraint-based phonology." In T. Alan Hall (ed.), Distinctive Feature Theory. Berlin: Mouton de Gruyter. Pp. 71-146.

Clements, G. N. and Elizabeth V. Hume. 1995. "The internal organization of speech sounds." In John Goldsmith (ed.), The Handbook of Phonological Theory. Cambridge, Mass.: Basil Blackwell. Pp. 245-306.

Dresher, B. Elan. 2002. "The contrastive hierarchy in phonology." Ms. University of Toronto.

Dresher, B. Elan and Xi Zhang. 2002. "Contrast and phonological patterning in Manchu vowel systems." Ms. University of Toronto.

Dugast, Idelette. 1971. Grammaire du tuncn. Paris: Klincksieck.

Goad, Heather. 1993. "On the configuration of height features." Ph.D. dissertation, University of Southern California.

Goldsmith, John. 1985. "Vowel harmony in Khalka Mongolian, Yaka, Finnish and Hungarian." Phonology (Yearbook) 2:253-275.

Goldsmith, John (ed.). 1993. "Harmonic phonology.” In John Goldsmith (ed.), The Last Phonological Rule, Chicago: University of Chicago Press. Pp. 21-60.

Harris, John. 1990. "Segmental complexity and phonological government." Phonology 7:255-300.

Harris, John. 1999. "Minimalist phonology." Colloquium presented at the University of California at Berkeley, April 1999. 
Harris, John and Geoff Lindsay. 1995. "The elements of phonological representations." In Jacques Durand and Francis Katamba (eds), Frontiers of Phonology: Atoms, Structures, Derivations. London: Longman. Pp. 34-79.

Hyman, Larry M. 1988. "Underspecification and vowel height transfer in Esimbi." Phonology 5:255-273.

Hyman, Larry M. 1993. "Problems in rule ordering in phonology: two Bantu test cases." In John Goldsmith (ed.), The Last Phonological Rule. Chicago: University of Chicago Press. Pp. 195-222.

Hyman, Larry M. To appear. "“Abstract' vowel harmony in Kàlòy: A systemdriven account." In Patrick Sauzet and Anne Zribi-Hertz (eds), Proceedings of the Conference "Théories Linguistiques et Langues Subsahariennes." Université de Paris VIII (St. Denis), February 6-8, 2000. Paris: l'Harmattan.

Karttunen, Lauri. 1993. "Finite-state constraints." In John Goldsmith (ed.), The Last Phonological Rule. Chicago: University of Chicago Press. Pp. 173-194.

Kenstowicz, Michael and Charles W. Kisseberth. 1979. Generative Phonology. Academic Press.

Koskienniemi, Kimmo. 1983. Two-Level Morphology: A General Computational Model for Word-form Recognition and Production. Publication \#11, Department of General Linguistics, Helsinki.

Kaye, Jonathan, Jean Lowenstamm, and Jean-Roger Vergnaud. 1985. "The intenal structure of phonological elements." Phonology (Yearbook) 2:305-328.

Lakoff, George. 1993. “Cognitive phonology.” In John Goldsmith (ed.), The Last Phonological Rule. Chicago: University of Chicago Press. Pp. 117-145.

McCarthy, John J. 1996. "Remarks on phonological opacity in optimality theory." In J. Lecarme, J. Lowenstamm and U. Shlonsky (eds), Studies in Afroasiatic grammar: Papers from the 2nd Conference on Afroasiatic Linguistics, The Hague: Holland Academic Graphics. Pp. 215-243.

McCarthy, John J. 1999. "Sympathy and phonological opacity." Phonology 16:331-399.

Meeussen, A. E. 1969 [1980]. Bantu Lexical Reconstructions. Tervuren: Koninklijk Museum voor Midden-Afrika. 
Mous, Maarten. 1986. "Vowel harmony in Tunen." In Koen Bogers, Harry van der Hulst, and Maarten Mous (eds), The Phonological Representation of Suprasementals, Dordrecht: Foris Publications. Pp. 281-295.

Mous, Maarten. 1987. "Review of Robinson (1983)." Journal of African Languages \& Linguistics 9:187-190.

Odden, David. 1991. "Vowel geometry." Phonology 8:261-289.

Orwig, Carol. 1989. "Extensions verbales en nugunu." In Daniel Barreteau and Robert Hedinger (eds), Descriptions de langues camerounaises, Paris: ORSTOM. Pp. 283-314.

Paulian, Christiane. 1980. "Les classes nominales dans les parlers yambassa." LACITO-informations, Bull. liaison 11: 63-66. Ivry: CNRS.

Paulian, Christiane. 1986a. "Les voyelles en nù-kàlònè: sept phonèmes, mais...." Cahiers du LACITO 1:51-65. Paris: CNRS.

Paulian, Christiane. 1986b. "Les parlers yambasa du Cameroun (Bantou A.62) (dialectométrie lexicale)." In Gladys Guarisma and Wilhelm J. G. Möhlig (eds), La méthode dialectométrique appliquée aux langues africaines, Berlin: Dietrich Reimer Verlag. Pp. 243-279.

Quilis, Antonio, Théophile Ambadiang and Victoria Marrero. 1990. "Phonologie et phonétique du gunu (langue bantu du Cameroun)." Travaux de Linguistique et de Philologie 28:343-377. Strasbourg-Nancy.

Rennison, John. 1987. "Vowel harmony and tridirectional vowel features." Folia Linguistica 21:337-354.

Robinson, Clinton. 1979. "Petit lexique gunu-français.” Yaoundé: Société Internationale de Linguistique.

Robinson, Clinton. 1983. Phonologie du gunu: parler yambassa. Paris: SELAF (CNRS).

Schane, Sanford A. 1984. "The fundamentals of particle phonology." Phonology (Yearbook) 1:129-155.

Stewart, John and Hélène van Leysnseele. 1979. "Underlying cross-height harmony in Nen (Bantu A.44)." Journal of African Languages and Linguistics $1: 31-54$.

Taylor, Carrie. 1985. Lexique nomaánté-français. Yaounde: SIL. 
van der Hulst, Harry, Maarten Mous, and Norval Smith. 1986. "The autosegmental analysis of reduced vowel harmony systems: the case of Tunen." In F. Beukema and A. Hulk (eds), Linguistics in the Netherlands 1986. Dordrecht. Foris Publications. Pp. 105-122.

van der Hulst, Harry and Norval Smith. 1985. "Vowel features and umlaut Djingili, Nyangumarda and Warlpiri." Phonology (Yearbook) 2:277-303.

van der Hulst, Harry and Jeroen van de Weijer. 1995. "Vowel harmony." In John A. Goldsmith (ed.), The Handbook of Phonological Theory, Cambridge, Mass.: Blackwell. Pp. 495-534.

Department of Linguistics

1203 Dwinelle Hall

University of California

Berkeley, CA 94720

hyman@socrates.berkeley.edu
[Received June 2002; accepted August 2002] 